\title{
Minimally invasive versus open right hepatectomy: comparative study with propensity score matching analysis
}

\author{
Vinícius Campos Duarte ${ }^{1^{*}} \mathbb{0}$, Fabricio Ferreira Coelho ${ }^{1}$, Alain Valverde ${ }^{2}$, Divia Danoussou², \\ Jaime Arthur Pirola Kruger ${ }^{1}$, Kevin Zuber ${ }^{3}$, Gilton Marques Fonseca' ${ }^{1}$, Vagner Birk Jeismann ${ }^{1}$, Paulo Herman ${ }^{1}$ \\ and Renato Micelli Lupinacci ${ }^{2,4,5}$
}

\begin{abstract}
Background: Minimally invasive liver resections (MILRs) have been increasingly performed in recent years. However, the majority of MILRs are actually minor or limited resections of peripheral lesions. Due to the technical complexity major hepatectomies remain challenging for minimally invasive surgery. The aim of this study was to compare the short and long-term outcomes of patients undergoing minimally invasive right hepatectomies (MIRHs) with contemporary patients undergoing open right hepatectomies (ORHs)

Methods: Consecutive patients submitted to anatomic right hepatectomies between January 2013 and December 2018 in two tertiary referral centers were studied. Study groups were compared on an intention-to-treat basis after propensity score matching (PSM). Overall survival (OS) analyses were performed for the entire cohort and specific etiologies subgroups

Results: During study period 178 right hepatectomies were performed. After matching, 37 patients were included in MIRH group and 60 in ORH group. The groups were homogenous for all baseline characteristics. MIRHs had significant lower blood loss $(400 \mathrm{ml}$ vs. $500 \mathrm{ml}, \mathrm{P}=0.01)$, lower rate of minor complications $(13.5 \% \mathrm{vs} .35 \%, \mathrm{P}=0.03)$ and larger resection margins ( $10 \mathrm{~mm}$ vs. $5 \mathrm{~mm}, \mathrm{P}=0.03$ ) when compared to ORHs. Additionally, a non-significant decrease in hospital stay ( $\mathrm{ORH} 9$ days vs. MIRH 7 days, $\mathrm{P}=0.09$ ) was observed. No differences regarding the use of Pringle's maneuver, operative time, overall morbidity or perioperative mortality were observed. OS was similar between the groups $(P=0.13)$. Similarly, no difference in OS was found in subgroups of patients with primary liver tumors $(P=0.09)$ and liver metastasis $(P=0.80)$.
\end{abstract}

Conclusions: MIRHs are feasible and safe in experienced hands. Minimally invasive approach was associated with less blood loss, a significant reduction in minor perioperative complications, and did not negatively affect long-term outcomes.

Keywords: Hepatectomy, Laparoscopy, Minimally invasive surgery, Hepatic neoplasms/surgery, Comparative study, Propensity score

\footnotetext{
*Correspondence: viniciuscduarte@hotmail.com

1 Liver Surgery Unit, Digestive Surgery Division, Department

of Gastroenterology, University of São Paulo School of Medicine, Rua

Dr. Enéas de Carvalho Aguiar, 255-9॰ Andar-sala 9025, São Paulo, SP CEP

05403-900, Brazil

Full list of author information is available at the end of the article
}

\section{Background}

Minimally invasive liver resections (MILRs) have been increasingly performed in recent years. The available results have shown its safety, feasibility, and potential benefits over open liver resections (OLRs) $[1,2]$. Observational studies and meta-analysis showed that 
laparoscopy decreased intraoperative bleeding, postoperative complications, and length of hospital stay when compared with OLRs [2, 3]. Recently, robotic-assisted surgery has been described as an alternative to laparoscopy for MILRs, with equivalent results for both short and long-term outcomes [4-6].

Although an impressive outspreading has been observed, most MILRs are actually minor or limited resections of peripheral lesions, mainly located in the anterolateral segments of the liver $[3,7,8]$. Due to the complexity of the operation and concerns about safety, major hepatectomies (resection of $\geq 3$ contiguous segments) and notably anatomical right hepatectomies remain challenging for minimally invasive surgery [9-11].

Thus, the aim of this study was to compare the short and long-term outcomes of patients undergoing minimally invasive right hepatectomies (MIRHs) with contemporary patients undergoing conventional open right hepatectomies (ORHs) from two tertiary referral centers.

\section{Methods}

Data of consecutive patients undergoing minimally invasive (laparoscopic and robotic) and open major hepatectomies between January 2013 and December 2018 were collected from prospective databases maintained by two tertiary referral centers. For the purpose of this study, only anatomical right hepatectomies were included. The Ethics Committee of both institutions approved this research protocol. The study was conducted following STROBE (Strengthening the Reporting of Observational studies in Epidemiology) recommendations [12].

The exclusion criteria were patients submitted to twostage hepatectomy or ALPPS (Associating liver partition and portal vein ligation for staged hepatectomy); surgery for hilar cholangiocarcinoma; synchronous colorectal and liver resections, and patients with incomplete data.

The indication for the surgical procedure was carried out after discussion in a multidisciplinary meeting. Patients were evaluated for suitability of the minimally invasive approach according to tumor location, quality of the non-tumoral liver parenchyma, and clinical status. Selection criteria for MIRH were one or more lesions completely resectable with an anatomical right hepatectomy. Patient characteristics, such as body mass index (BMI) or previous abdominal surgery, were not contraindications for MIRH. The only contraindications to MIRH were invasion of the inferior vena cava, invasion of the main right portal vein, and need for vascular or biliary reconstruction. The benign or malignant nature of the tumor was not a contraindication.

Liver resections were defined according to Brisbane terminology [13]. ORH was defined as those performed through incisions as J-shape incision, "Chevron" or
"Mercedes". Succinctly, ORH was performed as follows: first, a classical extrahepatic hilar approach or "glissonian approach" was performed. After inflow control, the right hemiliver was fully mobilized including dissection of the hepatic parenchyma from the inferior vena cava after ligation of accessories hepatic veins; at the end of the mobilization right hepatic vein was encircled on a vessel loop. Finally, parenchyma transection was performed following the ischemic line using harmonic scalpel and bipolar forceps. Middle hepatic vein was preserved whenever it was possible without compromising surgical margins. Intermittent Pringle's maneuver was used if needed in order to reduce operative blood loss.

Laparoscopic resections were performed using 5 or 6 ports located in right hypochondrium. Patients were positioned in a 30-degree reverse-Trendelenburg position and camera was positioned at right midclavicular line. The pneumoperitoneum pressure was set to $12 \mathrm{mmHg}$. Right pedicle control was performed by classical extrahepatic hilar dissection or extrahepatic "glissonian approach" as previously described [14]. Laparoscopic ultrasound was used to localize intrahepatic lesions and identify vascular structures. Parenchyma transection was performed using harmonic scalpel and bipolar forceps and right hepatic vein was sectioned inside the liver parenchyma using stapler. Surgical specimen was retrieved through a Pfannenstiel incision.

Robotic cases were performed using the da Vinci Si Surgical System from Intuitive Surgical Inc. (Sunnyvale, USA) with four robotic arms. Patients were positioned in a 30-degree reverse-Trendelenburg position. A 12-mm trocar was used to place a camera and three $8-\mathrm{mm}$ ports were used for the instrument arms. Inflow vascular structures and the right biliary duct were dissected and then ligated with clips, Hem-o-locks or stapler. After complete right hemiliver mobilization, the liver parenchyma was divided with a combination of harmonic scalpel and the bipolar forceps. A "drop-in" ultrasound was used to localize intrahepatic lesions and identify vascular structures. Finally, right hepatic vein was sectioned inside the liver parenchyma using stapler.

The following preoperative characteristics were studied: age, gender, BMI, preoperative laboratory tests, presence of comorbidities, American Society of Anesthesiologists (ASA) physical status score, diagnosis, size and location of the lesions, previous abdominal surgeries, and presence of chronic liver disease. Perioperative variables studied were: operative time, estimated blood loss (EBL), pedicle clamping time, transfusion requirement, conversion rate, length of hospital stay, postoperative complications, rehospitalization and mortality.

Postoperative morbidity was defined as complications occurring during the first 90 postoperative days and was 
stratified according to the Dindo-Clavien classification [15]. Postoperative biliary fistula was defined following the criteria proposed by the International Study Group of Liver Surgery [16]. Postoperative mortality was defined as death within 90 days after liver resection.

On final pathology report, both the rate of radical resections (R0) and the width of tumor-free margin $(\mathrm{mm})$ were analyzed. Resections were defined as R0 when microscopically margins were $\geq 1 \mathrm{~mm}$ and $\mathrm{R} 1$ when margins were $<1 \mathrm{~mm}$. Overall survival (OS) was defined as the time interval between the date of liver resection and the date of death or the most recent date of follow-up if the patient was alive.

Primary outcome was overall morbidity rate. Additional outcomes considered to be of interest and help interpret the results were chosen as secondary outcomes and included: operative time, EBL, blood transfusion rate, free surgical margins, hospital stay, rehospitalization, and mortality.

\section{Statistical analysis}

Continuous data were expressed as median and interquartile range or mean and standard deviation. Comparisons were performed using Mann-Whitney $\mathrm{U}$ test or $\mathrm{T}$ test. Categorical variables were expressed as percentage and compared using Fisher's exact test or Chi-squared test. A P value $<0.05$ was considered statistically significant. OS was assessed using the Kaplan-Meier method and curves were compared with the log-rank test. Survival analyses were performed for the entire cohort and specific etiologies subgroups (malignant liver tumors and metastasis).

Propensity score matching (PSM) was used to control possible confounding bias [17]. The PSM was constructed using age, ASA score, number of nodules, previous abdominal surgery and diagnosis. The nearest neighbor method was used with a caliper of 0.20 . The histograms after adjustment (matched) are very similar while the histograms before adjustment (raw) were different (Fig. 1). Comparisons were performed on an intention-to-treat basis; therefore, converted procedures were maintained in the MIRH group.

\section{Results}

During the study period 178 right hepatectomies were performed in both centers, $47 \mathrm{MIRH}$ (including 16 robotassisted and 31 laparoscopic resections) and $131 \mathrm{ORH}$. After match by PSM, 37 patients were included in MIRH group and 60 in ORH group. Clinical characteristics of each group before and after matching are shown on Table 1.

Before matching significant differences between groups were observed, including higher frequency of cirrhosis in MIRH group ( $23.4 \%$ vs. $8.4 \%, \mathrm{P}=0.02)$, multiple nodules resected in MIRH group ( $78.7 \%$ vs. $56.5 \%, \mathrm{P}=0.03)$, and more patients submitted to previous abdominal surgery

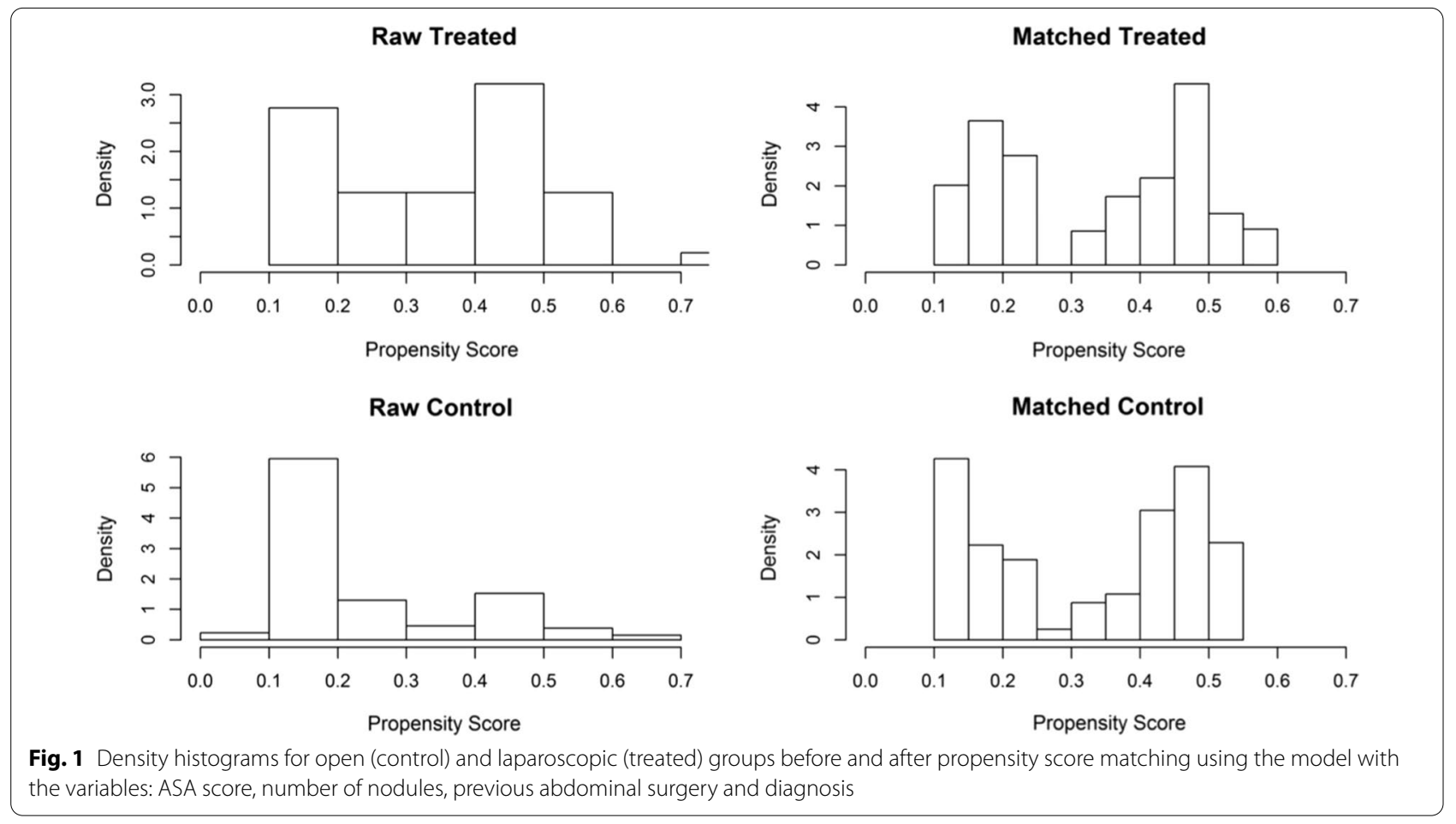




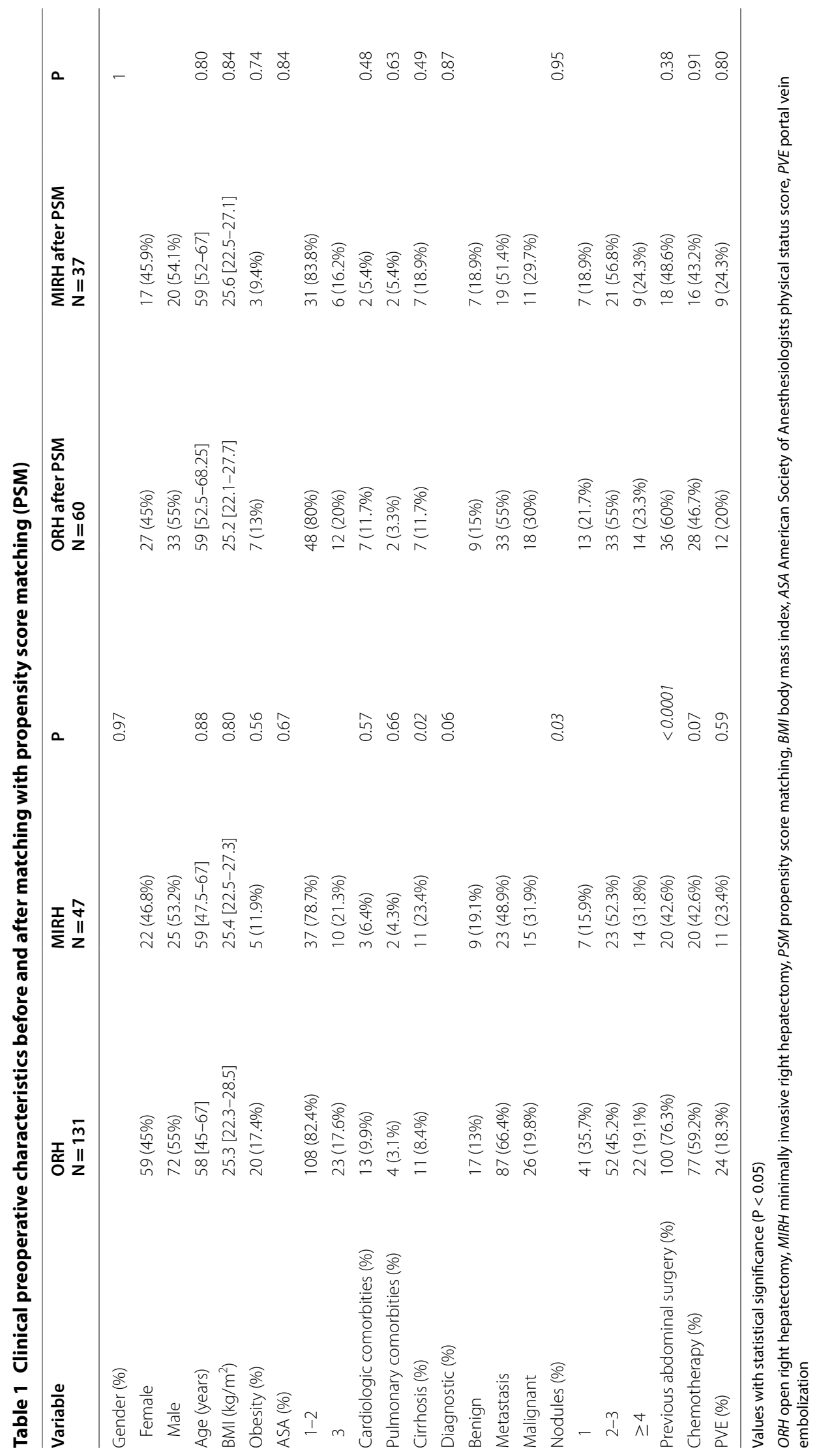


in ORH group ( $76.3 \%$ vs. $42.6 \%, \mathrm{P}<0.0001)$. After matching, the groups became homogenous for all baseline characteristics (Table 1 ).

Intraoperative results are shown on Table 2 . The conversion rate in the whole MIRH group was $4.2 \%$ (2 out of 47). After matching, conversion to open procedure was necessary in $5.4 \%$ (2 out of 37 ) of the cases, both due to technical difficulties and intraoperative bleeding. No difference regarding the use of Pringle's maneuver, clamping time and operative time was observed. Significant higher blood loss $(500 \mathrm{ml}$ vs. $400 \mathrm{ml}, \mathrm{P}=0.01)$ was observed in patients submitted to ORHs, despite no difference in blood transfusion rate was observed.

We observed a 2 days reduction in hospital stay in the MIRH group, although it did not reach statistical significance (ORH 9 days vs. MIRH 7 days, $\mathrm{P}=0.09)$. No significant difference was observed in overall morbidity between the groups (ORH 53.3\% vs. MIRH $35.1 \%$, $\mathrm{P}=0.09$ ); however, when stratified according to the Dindo-Clavien classification a lower rate of minor complications was observed in MIRH group (13.5\% vs. $35 \%$, $\mathrm{P}=0.03)$. No differences were found in liver-related complications, major complications and perioperative mortality (Table 3 ).

No difference on the clearance of surgical margins between groups was observed, but MIRHs showed larger resection margins (10 mm vs. $5 \mathrm{~mm}, \mathrm{P}=0.03)$. Survival analysis of the entire cohort after matching was similar between patients that underwent ORHs and MIRHs $(\mathrm{P}=0.13$, Fig. 2).

\section{Subgroup analysis}

Survival analysis was performed in 2 subgroups: patients with malignant liver tumors and patients with liver metastasis. In both subgroups no significant difference in OS was observed after matching (Fig. 3).

\section{Discussion}

The first MILRs reported at the beginning of the 1990s were basically wedge resections of peripheral lesions [18]. Subsequently, anatomic resections such as left lateral sectionectomy were performed [19]. The first major laparoscopic hepatectomy series was reported in 1997 by Hüscher et al. [20] using hybrid procedures for rightsided resections.

Although it has several theoretical advantages, only a small percentage of liver resections are actually performed by minimally invasive surgery. A recent French national database study showed that $15 \%$ of liver resections were performed through minimally invasive approach [21]. Similarly, Kim et al. [22] showed that less than $10 \%$ of all liver resections for benign lesions in the United States were minimally invasive.

Currently, minor laparoscopic resections in anterolateral segments and left lateral sectionectomy are considered the gold standard approach in many specialized centers [3, 8, 23]. However, resections of bilateral lesions, nodules in posterosuperior segments or in central locations of the liver (segments 1, 4a, 7, and 8), and major hepatectomies are still challenging [24, 25]. In fact, technical demands have limited major hepatectomies to highly-skilled surgeons in referral centers [10, 26]. Concerns during anatomical right liver resections are related to liver mobilization from the inferior vena cava, inflow and outflow control, and a large parenchymal transection area. Moreover, the learning curve for MILR can reach $45-75$ procedures [11, 27].

Technical limitations of laparoscopic major resections were depicted in a recent survey including 27 specialized centers. While minimally invasive approach was used in $61.8 \%$ of left lateral sectionectomies, this percentage decreased to $24.8 \%$ for major hepatectomies [28].

Robot-assisted surgery has been increasingly employed as an alternative to laparoscopy for MILR, mainly in

Table 2 Intraoperative outcomes before and after matching with propensity score matching (PSM)

\begin{tabular}{|c|c|c|c|c|c|c|}
\hline Variable & $\begin{array}{l}\text { ORH } \\
N=131\end{array}$ & $\begin{array}{l}\mathrm{MIRH} \\
\mathrm{N}=47\end{array}$ & $P$ & $\begin{array}{l}\text { ORH after PSM } \\
\mathrm{N}=60\end{array}$ & $\begin{array}{l}\text { MIRH after PSM } \\
\mathrm{N}=37\end{array}$ & $P$ \\
\hline Associated radiofrequency (\%) & $6(4.6 \%)$ & $1(2.1 \%)$ & 0.68 & $1(1.7 \%)$ & $1(2.7 \%)$ & 1 \\
\hline Pringle's maneuver (\%) & $36(27.5 \%)$ & $8(17 \%)$ & 0.17 & $17(28.3 \%)$ & $6(16.2 \%)$ & 0.26 \\
\hline $\begin{array}{l}\text { Clamping time (min) } \\
\text { Median (interquartile range) }\end{array}$ & $15[14.5-30]$ & $15[6.25-40]$ & 0.71 & $12[0-30]$ & $0[0-7.5]$ & 0.07 \\
\hline $\begin{array}{l}\text { Operative time (min) } \\
\text { Median (interquartile range) }\end{array}$ & $390[320-480]$ & $360[275-480]$ & 0.43 & 390 [322.5-480] & $360[260-491.25]$ & 0.42 \\
\hline $\begin{array}{l}\text { EBL (ml) } \\
\text { Median (interquartile range) }\end{array}$ & 500 [400-1000] & $475[250-675]$ & 0.007 & 500 [400-1000] & 400 [215-600] & 0.01 \\
\hline Transfusion (\%) & $37(28.2 \%)$ & $9(19.1 \%)$ & 0.25 & $17(28.3 \%)$ & $7(18.9 \%)$ & 0.42 \\
\hline
\end{tabular}

Values with statistical significance $(P<0.05)$

$\mathrm{ORH}$ open right hepatectomy, $M I R H$ minimally invasive right hepatectomy, EBL estimated blood loss 
Table 3 Postoperative results before and after propensity score matching (PSM)

\begin{tabular}{|c|c|c|c|c|c|c|}
\hline Variable & $\begin{array}{l}\text { ORH } \\
N=131\end{array}$ & $\begin{array}{l}\text { MIRH } \\
\mathrm{N}=47\end{array}$ & $P$ & $\begin{array}{l}\text { ORH after PSM } \\
\mathrm{N}=60\end{array}$ & $\begin{array}{l}\text { MIRH after PSM } \\
\mathrm{N}=37\end{array}$ & $P$ \\
\hline $\begin{array}{l}\text { Hospital stay (days) } \\
\text { Median (interquartile range) }\end{array}$ & $9[7-15]$ & $7[6-12.75]$ & 0.15 & $9[6-14.25]$ & $7[6-11]$ & 0.09 \\
\hline Reoperation (\%) & $4(3.1 \%)$ & $0(0 \%)$ & 0.57 & $3(5 \%)$ & $0(0 \%)$ & 0.28 \\
\hline Rehospitalization (\%) & $15(11.5 \%)$ & $4(8.5 \%)$ & 0.78 & $4(7.7 \%)$ & $4(11.8 \%)$ & 0.71 \\
\hline Overall morbidity (\%) & $71(54.2 \%)$ & $20(42.6 \%)$ & 0.17 & $32(53.3 \%)$ & $13(35.1 \%)$ & 0.09 \\
\hline \multicolumn{7}{|l|}{ Dindo-Clavien (\%) } \\
\hline$|-| \mid$ & $44(33.6 \%)$ & $9(19.1 \%)$ & 0.07 & $21(35 \%)$ & $5(13.5 \%)$ & 0.03 \\
\hline III-IV & $13(9.9 \%)$ & $11(23.4 \%)$ & 0.03 & $5(8.3 \%)$ & $8(21.6 \%)$ & 0.07 \\
\hline Perioperative mortality (\%) & $14(10.7 \%)$ & $0(0 \%)$ & 0.02 & $6(10 \%)$ & $0(0 \%)$ & 0.08 \\
\hline \multicolumn{7}{|l|}{ Liver-related complications } \\
\hline Hemorrhage (\%) & $4(3.1 \%)$ & $1(2.1 \%)$ & 1 & $1(1.7 \%)$ & $1(2.7 \%)$ & 1 \\
\hline Biliary fistula (\%) & $17(13 \%)$ & $5(10.6 \%)$ & 0.80 & $8(13.3 \%)$ & $5(13.5 \%)$ & 1 \\
\hline Ascites (\%) & $16(12.2 \%)$ & $4(8.5 \%)$ & 0.60 & $9(15 \%)$ & $2(5.4 \%)$ & 0.20 \\
\hline Encephalopathy (\%) & $4(3.1 \%)$ & $1(2.1 \%)$ & 1 & $3(5 \%)$ & $0(0 \%)$ & 0.28 \\
\hline $\begin{array}{l}\text { Size of largest lesion (mm) } \\
\text { Median (interquartile range) }\end{array}$ & $41.5[22-80]$ & 51.5 [25.75-75.75] & 0.35 & $50[22-102.5]$ & $55[25-78]$ & 0.69 \\
\hline $\begin{array}{l}\text { Surgical margins (\%) } \\
\text { Free }\end{array}$ & $115(87.8 \%)$ & $40(85.1 \%)$ & 0.62 & $55(91.7 \%)$ & 34 (91.9\%) & 1 \\
\hline $\begin{array}{l}\text { Margin width (mm) } \\
\text { Median (interquartile range) }\end{array}$ & $5[1-9.5]$ & $15[5-77.5]$ & 0.0002 & $5[2-9.5]$ & $10[5-25]$ & 0.03 \\
\hline
\end{tabular}

Values with statistical significance $(P<0.05)$

$\mathrm{ORH}$ open right hepatectomy, $M I R H$ minimally invasive right hepatectomy

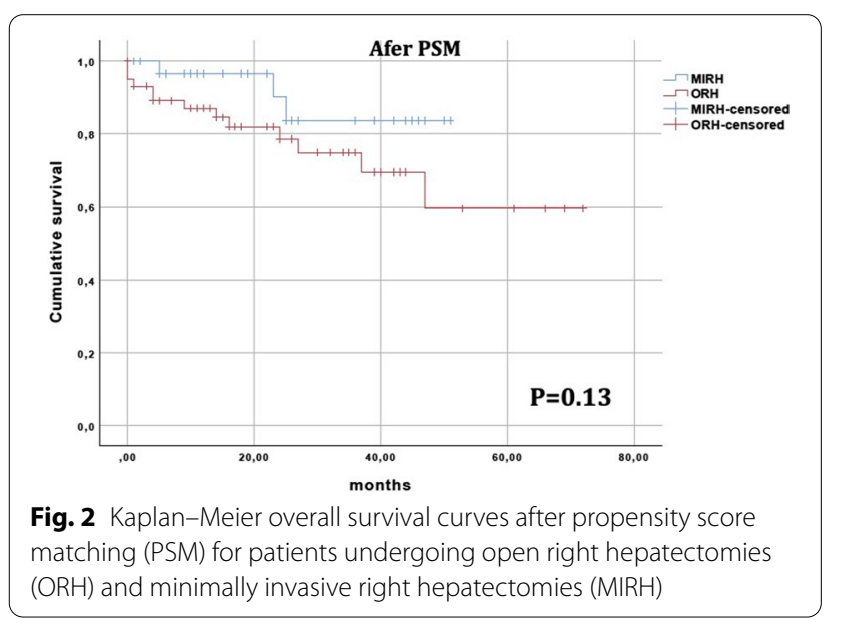

complex and major liver resections [29, 30]. Despite potential advantages, most of the available evidence demonstrated similar results between laparoscopic and robotic liver resections $[5,31,32]$.

Few studies were addressed to study the results of minimally invasive major hepatectomies [10, 26, 33]. Only recently observational studies with high methodological quality have been published comparing open and minimally invasive major resections $[34,35]$. Takahara et al.
[36] using PSM showed advantages in terms of blood loss, length of hospital stay, and complications with the laparoscopic approach.

We observed a conversion rate of $5.4 \%$, lower than observed in other series raging from 9 to $42 \%$. Cipriani et al. [37] showed an $11 \%$ conversion rate in a European multicenter study. Similarly, Kasai et al. [33] observed a $17.7 \%$ conversion rate in a recent meta-analysis of individual data.

MILR is frequently associated with a longer operative time $[34,35]$. However, we did not find any significant difference in operative time for patients undergoing MIRH. This finding can be explained by the increased experience with MILR, showing that the learning curve was overcome and surgical steps have been standardized to entail a significant reduction in operative time $[38,39]$. In fact, were included in our study patients that underwent hepatectomy between 2013 and 2018, after overcome the learning curve with MILRs. Minimally invasive liver surgery program started at the University of São Paulo in 2005 and at the Diaconesses Croix Saint Simon Hospital in 2010. The 2 centers altogether have performed more than 550 minimally liver resections.

In accordance with previous studies [34, 36], we observed a significantly lower blood loss in the MIRH group. Factors that may have influenced this reduction 

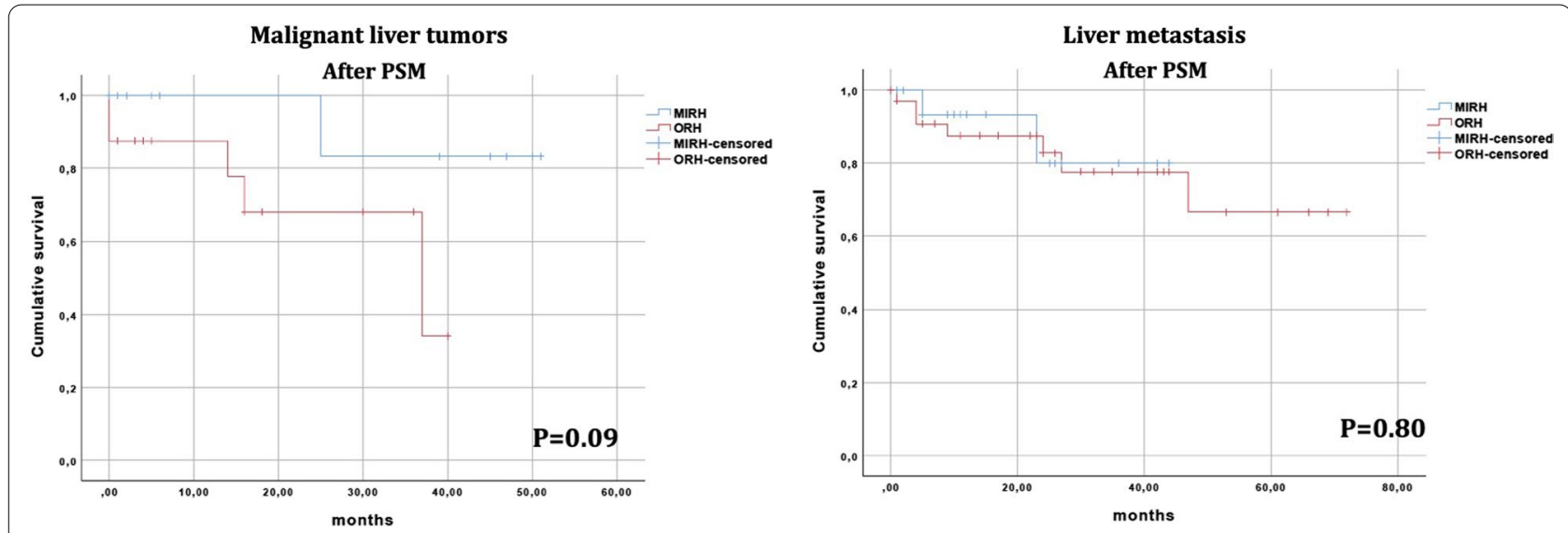

Fig. 3 Overall survival curves for subgroups of patients with primary liver tumors and liver metastasis after propensity score matching (PSM). ORH open right hepatectomy, MIRH minimally invasive right hepatectomy

are the development of new energy devices for liver transection, the image magnification afforded by laparoscopy, the pneumoperitoneum, and the widespread use of linear staplers for controlling hepatic pedicles and large vessels [1].

Several authors found a reduction in perioperative complications in the MILR group [36, 37]. However, in our study the overall morbidity (our primary endpoint) presented a non-significant decrease $(35.1 \%$ vs. $53.3 \%, \mathrm{P}=0.09$ ), probably related to the small sample size of our casuistry. Although non statistically significant, this finding appears to be clinically relevant. Our data showed a decrease in Dindo-Clavien I-II complications $(13.5 \%$ vs. $35 \%, \mathrm{P}=0.03)$, in accordance with the findings of a recent meta-analysis [33].

The reduction of hospital stay is an outcome frequently attributed to minimally invasive surgery $[2,36]$. We observed a 2-day reduction in the MIRH group. Although not statistically significant, we considered this a consistent clinical benefit for patients subjected to major liver resections.

Concerning the oncological outcomes, there was no increase in R1 resections in MIRH group. This data is in accordance with other studies that found similar R0 resections, and wider margins associated with MILRs when compared to OLRs $[2,40]$.

Few comparative studies assessed the long-term results of minimally invasive resections [33, 41]. The fear of inferior oncological results in patients undergoing MILRs was not demonstrated by the available studies $(33,35)$. Similarly, in our study the OS rate in MIRH group was not inferior when compared to isolated ORH group. The same finding was observed in subgroups of patients operated for primary liver tumor and liver metastases.
Our study has the classical drawbacks of any retrospective analyses. For this reason, we focused only in right anatomical liver resections. Moreover, in order to minimize selection bias we excluded complex or associated procedures such as two-stage hepatectomies, hilar cholangiocarcinoma and synchronous resections. Finally, we used the PSM and observed that after matching, both groups were homogeneous in the main clinical and surgical characteristics. PSM was used to limit observed confounding factors, however it is important to state that PSM does not allow us to control for possible selection bias. Also, by introducing secondary outcomes and performing other comparisons, we could have increased the alfa risk and decay our results. Altogether, these points may limit the extent to which we can generalize our findings.

\section{Conclusion}

In this bicentric study, MIRHs performed by experienced surgeons were feasible and safe. Compared with matched patients submitted to $\mathrm{ORH}$, minimally invasive approach was associated with less blood loss, a significant reduction in minor perioperative complications and did not negatively affect long-term outcomes.

\section{Abbreviations}

MILRs: Minimally invasive liver resections; OLRs: Open liver resections; MIRHs: Minimally invasive right hepatectomies; ORHs: Open right hepatectomies; PSM: Propensity score matching; OS: Overall survival; STROBE: Strengthening the Reporting of Observational studies in Epidemiology; ALPPS: Associating liver partition and portal vein ligation for staged hepatectomy; BMI: Body mass index; ASA: American Society of Anesthesiologists; EBL: Estimated blood loss.

\section{Acknowledgements}

We would like to thank Oddone Freitas Melro Braghiroli, a statistician and surgeon who helped us with the statistical analysis and answer the reviewers' considerations. 


\section{Authors' contributions}

FC, PH and RL conceived the original study and design. AV and DD contributed to the study's design. KZ was responsible for the statistical analysis. FC, $\mathrm{VD}, \mathrm{RL}$ participated in conducting the study. VD, AV, DD, JK, VJ, GF and FC are responsible for data collection, data recording and preparing the manuscript. All authors read and approved the final manuscript.

\section{Funding}

Not applicable.

\section{Availability of data and materials}

The datasets used and/or analysed during the current study are available from the corresponding author on reasonable request.

\section{Ethics approval and consent to participate}

This study does not require a free and informed consent term because a search was carried out in a database maintained by two tertiary referral centers, which did not require contact with the patient and did not offer risks. This study was approved by the institutional review board of the Hospital das Clínicas of University of Sao Paulo School of Medicine (Approval number: 12741) chaired by MD Maria Aparecida Azevedo Koike Folgueira and by the instutional review board of the Groupe Hospitalier Diaconesses Croix Saint Simon chaired by MD Thierry Lazard.

\section{Consent for publication}

Not applicable.

\section{Competing interests}

The authors declare that they have no competing interests.

\section{Author details}

${ }^{1}$ Liver Surgery Unit, Digestive Surgery Division, Department of Gastroenterology, University of São Paulo School of Medicine, Rua Dr. Enéas de Carvalho Aguiar, 255-90 Andar-sala 9025, São Paulo, SP CEP 05403-900, Brazil. ${ }^{2}$ Digestive Surgery Unit, Diaconesses Croix Saint Simon Hospital, 125, Rue d'Avron, 75020 Paris, France. ${ }^{3}$ Research and Biostatistics Unit, Rothschild Foundation Hospital, Paris, France. ${ }^{4}$ AP-HP, Department of Digestive, Oncologic and Metabolic Surgery, Ambroise Paré Hospital, Boulogne-Billancourt, France. ${ }^{5}$ Versailles St-Quentin-en-Yvelines/Paris Saclay University, UFR des Sciences de la Santé Simone Veil, Montigny-Le-Bretonneux, France.

Received: 17 June 2020 Accepted: 20 October 2020

Published online: 30 October 2020

\section{References}

1. Coelho FF, Kruger JAP, Fonseca GM, Araujo RLC, Jeismann VB, Perini MV, et al. Laparoscopic liver resection: experience based guidelines. World J Gastrointestinal Surg. 2016;8(1):5-26.

2. Ciria R, Cherqui D, Geller DA, Briceno J, Wakabayashi G. Comparative short-term benefits of laparoscopic liver resection: 9000 cases and climbing. Ann Surg. 2016;263(4):761-77.

3. Macacari RL, Coelho FF, Bernardo WM, Kruger JAP, Jeismann VB, Fonseca GM, et al. Laparoscopic vs open left lateral sectionectomy: an update meta-analysis of randomized and non-randomized controlled trials. Int J Surg. 2019;61:1-10.

4. Tee MC, Chen L, Peightal D, Franko J, Kim PT, Brahmbhatt RD, et al. Minimally invasive hepatectomy is associated with decreased morbidity and resource utilization in the elderly. Surg Endosc. 2019. https://doi. org/10.1007/s00464-019-07298-5.

5. Guan R, Chen Y, Yang K, Ma D, Gong X, Shen B, et al. Clinical efficacy of robot-assisted versus laparoscopic liver resection: a meta analysis. Asian J Surg. 2019;42(1):19-31.

6. Beard RE, Khan S, Troisi RI, Montalti R, Vanlander A, Fong Y, et al. Longterm and oncologic outcomes of robotic versus laparoscopic liver resection for metastatic colorectal cancer: a multicenter, propensity score matching analysis. World J Surg. 2019;44:887.
7. Kingham TP, Leung U, Kuk D, Gonen M, D'Angelica MI, Allen PJ, et al. Robotic liver resection: a case-matched comparison. World J Surg. 2016:40(6):1422-8.

8. Buell JF, Cherqui D, Geller DA, O'Rourke N, lannitti D, Dagher I, et al. The international position on laparoscopic liver surgery: the Louisville Statement, 2008. Ann Surg. 2009;250(5):825-30.

9. Ban D, Tanabe M, Ito H, Otsuka Y, Nitta H, Abe Y, et al. A novel difficulty scoring system for laparoscopic liver resection. J Hepatobiliary Pancreat Sci. 2014;21(10):745-53.

10. Dagher I, Gayet B, Tzanis D, Tranchart H, Fuks D, Soubrane O, et al. International experience for laparoscopic major liver resection. J Hepatobiliary Pancreat Sci. 2014;21(10):732-6.

11. Nomi T, Fuks D, Kawaguchi Y, Mal F, Nakajima Y, Gayet B. Learning curve for laparoscopic major hepatectomy. Br J Surg. 2015;102(7):796-804.

12. von Elm E, Altman DG, Egger M, Pocock SJ, Gotzsche PC, Vandenbroucke JP. The Strengthening the Reporting of Observational Studies in Epidemiology (STROBE) statement: guidelines for reporting observational studies. J Clin Epidemiol. 2008;61(4):344-9.

13. Belghiti J, Clavien P, Gadzijev E, Garden JO, Lau W, Makuuchi M, et al. The Brisbane 2000 terminology of liver anatomy and resections. 2000.

14. Krüger JA, Fonseca GM, Coelho FF, Jeismann V, Herman P. Laparoscopic right hepatectomy for cirrhotic patients: Takasaki's hilar control and caudal approach. Ann Surg Oncol. 2017;24(2):558-9.

15. Dindo D, Demartines N, Clavien PA. Classification of surgical complications: a new proposal with evaluation in a cohort of 6336 patients and results of a survey. Ann Surg. 2004;240(2):205-13.

16. Koch M, Garden OJ, Padbury R, Rahbari NN, Adam R, Capussotti L, et al. Bile leakage after hepatobiliary and pancreatic surgery: a definition and grading of severity by the International Study Group of Liver Surgery. Surgery. 2011;149(5):680-8.

17. Desai RJ, Franklin JM. Alternative approaches for confounding adjustment in observational studies using weighting based on the propensity score: a primer for practitioners. BMJ. 2019;367:15657.

18. Reich H, McGlynn F, DeCaprio J, Budin R. Laparoscopic excision of benign liver lesions. Obstet Gynecol. 1991;78(5 Pt 2):956-8.

19. Azagra JS, Goergen M, Gilbart E, Jacobs D. Laparoscopic anatomical (hepatic) left lateral segmentectomy-technical aspects. Surg Endosc. 1996;10(7):758-61.

20. Huscher CG, Lirici MM, Chiodini S, Recher A. Current position of advanced laparoscopic surgery of the liver. J R Coll Surg Edinb. 1997;42(4):219-25.

21. Farges O, Goutte N, Dokmak S, Bendersky N, Falissard B. How surgical technology translates into practice: the model of laparoscopic liver resections performed in France. Ann Surg. 2014;260(5):916-21.

22. Kim Y, Amini N, He J, Margonis GA, Weiss M, Wolfgang CL, et al. National trends in the use of surgery for benign hepatic tumors in the United States. Surgery. 2015;157(6):1055-64

23. Herman P, Perini MV, Coelho F, Saad W, D'Albuquerque LAC. Half-Pringle Maneuver: a useful tool in laparoscopic liver resection. J Laparoendosc Adv Surg Tech. 2010;20(1):35-7.

24. Wakabayashi G, Cherqui D, Geller DA, Buell JF, Kaneko H, Han HS, et al. Recommendations for laparoscopic liver resection: a report from the second international consensus conference held in Morioka. Ann Surg. 2015;261(4):619-29.

25. Herman P, Kruger JAP, Perini MV, Coelho FF, Lupinacci RM. Laparoscopic hepatic posterior sectionectomy: a hand-assisted approach. Ann Surg Oncol. 2013;20(4):1266.

26. Dagher I, O'Rourke N, Geller DA, Cherqui D, Belli G, Gamblin TC, et al. Laparoscopic major hepatectomy: an evolution in standard of care. Ann Surg. 2009;250(5):856-60.

27. Lee W, Woo JW, Lee JK, Park JH, Kim JY, Kwag SJ, et al. Comparison of learning curves for major and minor laparoscopic liver resection. J Laparoendosc Adv Surg Tech A. 2016;26(6):457-64.

28. Kawaguchi Y, Hasegawa K, Wakabayashi G, Cherqui D, Geller DA, Buell $J F$, et al. Survey results on daily practice in open and laparoscopic liver resections from 27 centers participating in the second International Consensus Conference. J Hepatobiliary Pancreat Sci. 2016;23(5):283-8.

29. Efanov M, Alikhanov R, Tsvirkun V, Kazakov I, Melekhina O, Kim P, et al. Comparative analysis of learning curve in complex robot-assisted and laparoscopic liver resection. HPB (Oxford). 2017;19(9):818-24. 
30. Fruscione M, Pickens R, Baker EH, Cochran A, Khan A, Ocuin L, et al. Robotic-assisted versus laparoscopic major liver resection: analysis of outcomes from a single center. HPB (Oxford). 2019;21(7):906-11.

31. Montalti R, Berardi G, Patriti A, Vivarelli M, Troisi RI. Outcomes of robotic vs laparoscopic hepatectomy: a systematic review and meta-analysis. World J Gastroenterol. 2015;21(27):8441-51.

32. Kim JK, Park JS, Han DH, Choi GH, Kim KS, Choi JS, et al. Robotic versus laparoscopic left lateral sectionectomy of liver. Surg Endosc. 2016;90:8.

33. Kasai M, Cipriani F, Gayet B, Aldrighetti L, Ratti F, Sarmiento JM, et al. Laparoscopic versus open major hepatectomy: a systematic review and meta-analysis of individual patient data. Surgery. 2018;163(5):985-95

34. Tozzi F, Berardi G, Vierstraete M, Kasai M, de Carvalho LA, Vivarelli M, et al. Laparoscopic versus open approach for formal right and left hepatectomy: a propensity score matching analysis. World J Surg. 2018;42(8):2627-34.

35. Xu HW, Liu F, Li HY, Wei YG, Li B. Outcomes following laparoscopic versus open major hepatectomy for hepatocellular carcinoma in patients with cirrhosis: a propensity score-matched analysis. Surg Endosc 2018;32(2):712-9.

36. Takahara T, Wakabayashi G, Konno H, Gotoh M, Yamaue H, Yanaga K, et al. Comparison of laparoscopic major hepatectomy with propensity score matched open cases from the National Clinical Database in Japan. J Hepatobiliary Pancreat Sci. 2016;23(11):721-34.

37. Cipriani F, Alzoubi M, Fuks D, Ratti F, Kawai T, Berardi G, et al. Pure laparoscopic versus open hemihepatectomy: a critical assessment and realistic expectations - a propensity score-based analysis of right and left hemihepatectomies from nine European tertiary referral centers. J Hepatobiliary Pancreat Sci. 2019;22:404.

38. Coelho FF, Kruger JAP, Jeismann VB, Fonseca GM, Makdissi FF, Ferreira $L A$, et al. Are hybrid liver resections truly minimally invasive? A propensity score matching analysis. J Laparoendosc Adv Surg Tech A. 2017;27(12):1236-44.

39. Chen PD, Wu CY, Hu RH, Chen CN, Yuan RH, Liang JT, et al. Robotic major hepatectomy: Is there a learning curve? Surgery. 2017;161(3):642-9.

40. Zhang XL, Liu RF, Zhang D, Zhang YS, Wang T. Laparoscopic versus open liver resection for colorectal liver metastases: a systematic review and meta-analysis of studies with propensity score-based analysis. Int I Surg. 2017:44:191-203.

41. Wang ZY, Chen QL, Sun LL, He SP, Luo XF, Huang LS, et al. Laparoscopic versus open major liver resection for hepatocellular carcinoma: systematic review and meta-analysis of comparative cohort studies. BMC Cancer 2019;19(1):1047.

\section{Publisher's Note}

Springer Nature remains neutral with regard to jurisdictional claims in published maps and institutional affiliations.
Ready to submit your research? Choose BMC and benefit from:

- fast, convenient online submission

- thorough peer review by experienced researchers in your field

- rapid publication on acceptance

- support for research data, including large and complex data types

- gold Open Access which fosters wider collaboration and increased citations

- maximum visibility for your research: over $100 \mathrm{M}$ website views per year

At BMC, research is always in progress.

Learn more biomedcentral.com/submissions 